\title{
Improving the UAV-based yield estimation of paddy rice by using the solar radiation of geostationary satellite Himawari-8
}

\author{
Akira Hama ${ }^{1}$, Kei Tanaka ${ }^{2}$, Atsushi Mochizuki ${ }^{3}$, Yasuo Tsuruoka ${ }^{3}$ and Akihiko Kondoh ${ }^{4}$ \\ ${ }^{1}$ College of Education, Yokohama National University, Japan \\ 2Japan Map Center, Japan \\ ${ }^{3}$ Chiba Prefectural Agriculture and Forestry Research Center, Japan \\ ${ }^{4}$ Center for Environmental Remote Sensing, Chiba University, Japan
}

\begin{abstract}
:
The objectives of this study were to improve the yield estimation of paddy rice based on the unmanned aerial vehicle remote sensing (UAV-RS) and solar radiation data sets. The study used the UAV-RS-based normalized difference vegetation index (NDVI) at the heading stage, the solar radiation data of geostationary satellite Himawari-8 and the solar radiation data of polar orbiting satellite Aqua/ MODIS. A comparison of two satellite-based solar radiation data sets (Himawari-8 and MODIS PAR) showed that the coefficient of determination $\left(R^{2}\right)$ of estimated yield based on Himawari-8 solar radiation was 0.7606 while the $R^{2}$ of estimated yield based on the MODIS PAR was 0.4749 . Additionally, the root mean square error (RMSE) of Himawari-8 solar radiation was $26.5 \mathrm{~g} / \mathrm{m}^{2}$ while the RMSE of estimated yield based on the MODIS PAR was $39.2 \mathrm{~g} / \mathrm{m}^{2}$ (The average observed yield was $489.3 \mathrm{~g} / \mathrm{m}^{2}$ ). The Estimated yield based on Himawari-8 solar radiation, therefore, outperformed the MODIS PAR-based estimated yield. The improvement of the temporal resolution of the satellite-based dataset allowed by using the Himawari- 8 data set contributed to the improvement of estimation accuracy. Satellite-based solar radiation data allow yield estimation based on remote sensing in regions where there are no ground observation data of solar radiation.
\end{abstract}

KEYWORDS drone; smart farming; field data; solar radiation

\section{INTRODUCTION}

One especially distinctive feature of monsoon Asia is its extremely high share of global rice production. Worldwide, approximately $90 \%$ of all rice acreage and of total annual rice output is concentrated in the region, making it rightly deserving of the title "rice granary of the world" (Kyuma, 2004). In monsoon Asia, rapid population growth is driving food demand, and the number of farmers there classified as smallholders is also increasing (High Level Panel of Experts on Food Security and Nutrition, 2013). Smallholder agriculture accounts for the majority of agricultural production in monsoon Asia, and it is the foundation of food security among countries in the region (High Level Panel of Experts on Food Security and Nutrition, 2013). Smallholder agriculture is practiced by families (i.e. households containing one or more people) who rely mostly (or solely) on family labor and derive a large but variable share of their income - in kind or in cash - from that work (High Level Panel of Experts on Food Security and Nutrition, 2013). Therefore, although smallholders may use fields that are small and complicated to measure, such measurement is crucial to accurately estimating yields and ensuring a stable household food supply (Maki et al., 2017).

Crop models are useful in estimating yields; they leverage various methods, depending on the scale of the target. Yield estimation models that can be applied at the global scale, such as a simulation model for rice-weather relations (e.g. SIMRIW) (Horie et al., 1995), require only cultivar information and meteorological data. Hence, the outputs of the model indicate the potential yield of the region without considering factors such as water management and fertilizer treatment (Maki et al., 2017). Field-scale models such as ORYZA2000 (Bouman, 2001) can simulate each field's yield while considering water management and fertilizer treatment; however, this type of model requires specific data for each field, including water management practices and the amount of fertilizer used. Thus, it is difficult to apply this model in regions where field-based data are insufficient (Maki et al., 2017).

Meanwhile, some crop yield estimation researchers use remote sensing (Ren et al., 2008; Peng et al., 2014; Boschetti et al., 2015; Foster et al., 2017; Wang et al., 2017). The most popular yield estimation method used in these studies leverages a regression model between a spectral index and the observed yield (Nuarsa et al., 2011; Foster et al., 2017; Wang et al., 2017). While this method is simple and can estimate yields at the regional level, it does not consider growth conditions (e.g. meteorological data, water stress, and nitrogen stress); therefore, it is an empirical model whose accuracy depends on the research location. In recent years, another approach to the integration of remote sensing into crop models has obtained sound results (Curnel et al., 2011; Zhao et al., 2013; Homma et al., 2017; Maki et al., 2017). In this type of model, the crop model parameters are adjusted while comparing the crop model-

Correspondence to: Akira Hama, College of Education, Yokohama National University, 79-2 Tokiwadai, Hodogaya-ku, Yokohama, Kanagawa 240-8501, Japan. E-mail: hama-akira-ck@ynu.ac.jp 


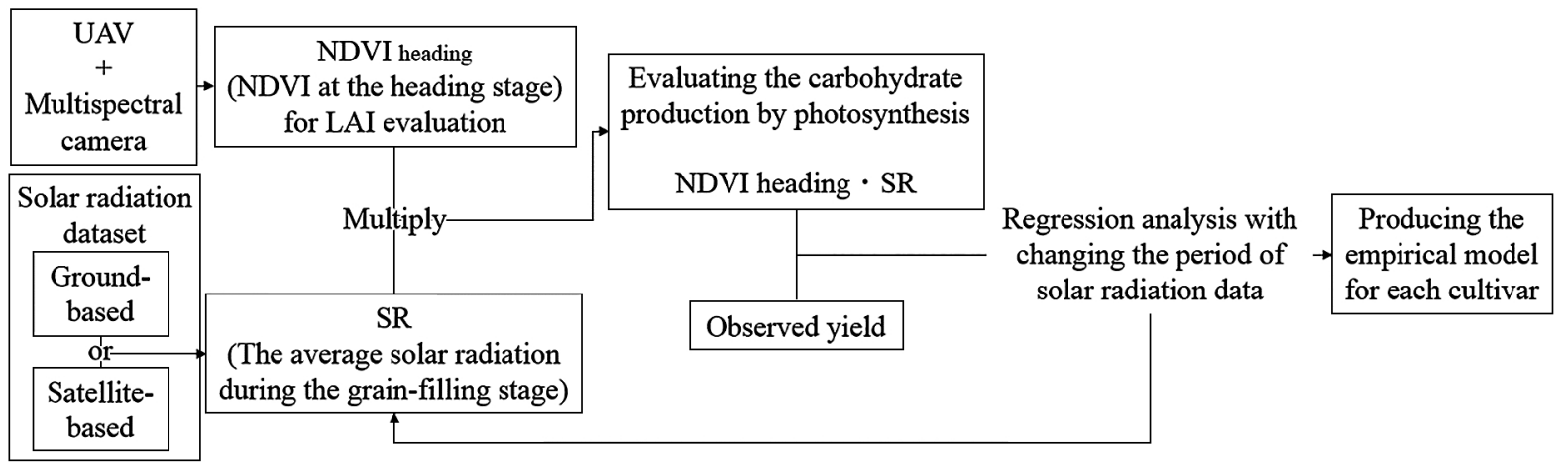

Figure 1. The overall framework of the method for the yield estimation used in this study

based simulated leaf area index (LAI) and the LAI estimated through remote sensing.

The integration of remote sensing data into crop models has resulted in successful estimations of field-scale yield. However, satellite-based optical remote sensing is difficult to use in monsoon Asia during the wet season, because of cloud cover. Additionally, the field sizes are small and variable, and the use of high-resolution spatial images is preferable, to avoid mixed pixels. Unmanned aerial vehicles (UAVs), also called drones, have a distinct advantage at this point: UAV-based yield estimation has been investigated as a means of estimating field-level crop yield (Stroppiana et al., 2015; Mosleh et al., 2016; Teoh et al., 2016). These studies apply a regression model between a spectral index and the observed yield, for yield estimation purposes.

In a crop model, the accuracy of the simulated LAI is important for yield estimation, because the yield is estimated through the accumulation of carbohydrate production during the grain-filling stage - something that is, in turn, estimated using LAI and solar radiation data. Therefore, for yield estimation purposes, a simple estimation model that uses only LAI and solar radiation data can be created. Hama et al. (2018) demonstrated the robustness of a paddy rice yield estimation model that uses UAV remote sensing (UAV-RS) and solar radiation information. This method is shown in Figure 1 and Equation (1).

$$
y=N D V I_{\text {heading }} S R+b,
$$

where $y$ is the yield $\left(\mathrm{g} / \mathrm{m}^{2}\right), a$ is the slope, $N D V I_{\text {heading }}$ is the normalized difference vegetation index (NDVI) at the heading stage, $S R$ is the average solar radiation during the grainfilling stage $\left(\mathrm{MJ} / \mathrm{m}^{2} /\right.$ day), and $b$ is the intercept. The NDVI at the heading stage is used in LAI evaluation, and solar radiation during the grain-filling stage is used in photosynthesis evaluation. Each cultivar is different in terms of yield and growth rate; hence, regression analysis is needed when changing the period of the solar radiation data, and an empirical model needs to be created for each cultivar.

Hama et al. (2018) demonstrated a simple but widely applicable yield estimation model for paddy rice. However, the model results were strongly affected by the accuracy of the solar radiation dataset. When using MODIS-based solar radiation data (Frouin and Murakami, 2007), the accuracy of the estimated yield was worse than that derived by using meteorological station data. On October 7, 2014, the Japan
Meteorological Agency launched Himawari-8, the eighth Japanese geostationary meteorological satellite, and it became operational on July 7, 2015 (Yumimoto et al., 2016). This satellite offers access to satellite-based solar radiation data at a high spatial-temporal resolution. In the current study, we attempt yield estimation through the use of UAV-RS and a satellite-based solar radiation dataset from Himawari-8, and verify the accuracy of this method (Hama et al., 2018).

\section{MATERIALS AND METHODS}

\section{Study sites and UAV data acquisition}

We analyzed a UAV-RS dataset for paddy rice (Oryza sativa L. cv. Koshihikari) captured at the Chiba and Saitama sites (Figure 2). At the Chiba site, test fields were subdivided into 48 compartments that featured various cultivation conditions (i.e. transplanting date, cultivars, and fertilizer amount). Although three cultivars were cultivated at the Chiba site, in this study, the cultivar common to both the Chiba and Saitama sites was Koshihikari. Therefore, to verify the estimation results, we used a dataset containing only Koshihikari data. At the Saitama site, we established six compartments all featuring the same conditions (i.e. transplanting date, cultivars, and fertilizer amount) (Figure 2). Data pertaining to average yield were captured for each compartment.

The observation equipment included an electric-powered multicopter (enRoute Zion Pro800) and a multispectral camera (BIZWORKS Yubaflex). The Yubaflex is a modified version of the Canon PowerShot S100 camera, which captures images at the green, red, and near-infrared (NIR) bands. The bandwidth of each band was as follows: green, 500-600 nm; red, 600-850 nm; and NIR, 700-1050 nm. (The wavelength showing the maximum spectral response of each band was as follows: green, $550 \mathrm{~nm}$; red, $600 \mathrm{~nm}$; and NIR, $850 \mathrm{~nm}$ ). There were 12 million pixels in each image $(4000 \times 3000)$. The camera can also convert the observed digital number to radiance values, using the dedicated Yubaflex 3.1 software (Tokunaga and Moriyama, 2012).

UAV-based observations were acquired between 10:00 and 10:30 a.m. local time, under both clear and cloudy sky conditions. The flight altitude was $50 \mathrm{~m}$ above ground level (ground resolution: $1.8 \mathrm{~cm}$ ), and the overlap of each image 


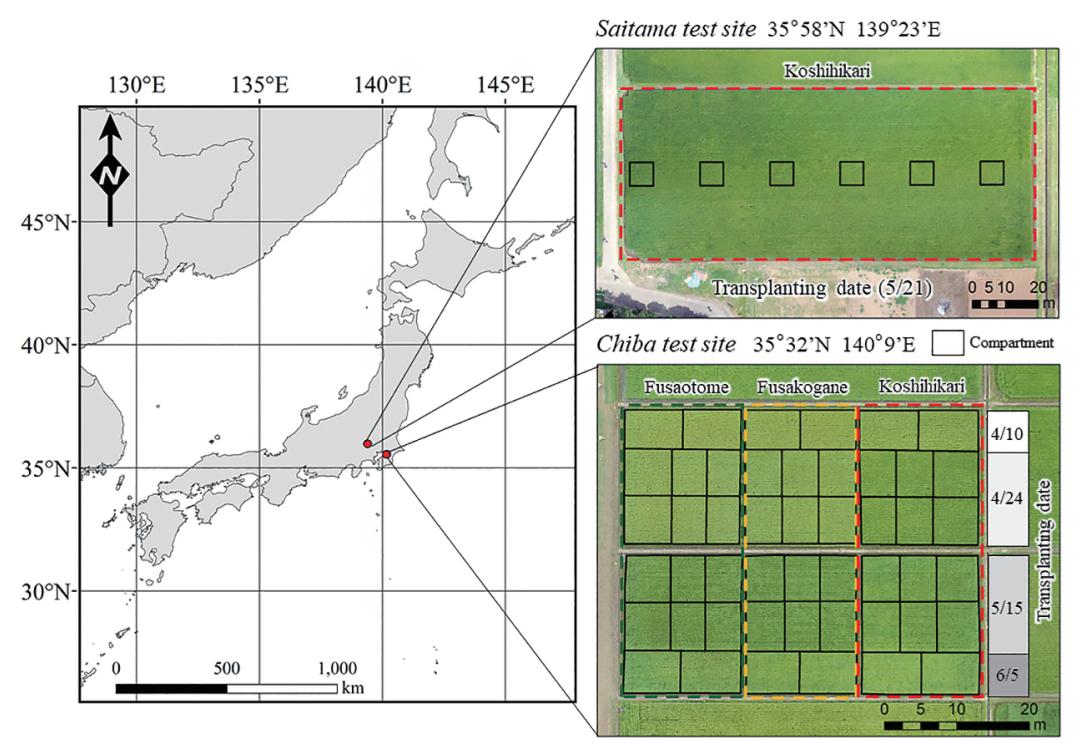

Figure 2. Test sites: Chiba Prefectural Agriculture and Forestry Research Center and Saitama test site: The black squares in the test sites show compartments for the yield estimation model validation. The yield was observed at each compartment

was $70 \%$. The settings of the Yubaflex were as follows: shutter speed priority mode, shutter speed set to $1 / 1000 \mathrm{~s}$, ISO sensitivity set to Auto, and interval of shooting set to the minimum value (about $4 \mathrm{~s}$ ).

\section{DATA AND ANALYSIS}

\section{Image processing}

After being converted to radiance values through the use of Yubaflex 3.1 software, the Yubaflex images were used to create orthomosaic images using structure from motionmultiview stereo software (Agisoft PhotoScan Professional v1.4.1). The NDVI was calculated based on Equation (2).

$$
N D V I=\left(N I R_{\text {Yubaflex }}-\operatorname{Red}_{\text {Yubaflex }}\right) /\left(N I R_{\text {Yubaflex }}+\operatorname{Red}_{\text {Yubaflex }}\right) \text {, }
$$

where $N D V I$ is the Yubaflex-based NDVI, and $N I R_{\text {Yubaflex }}$ and $R e d_{\text {Yubaflex }}$ are the Yubaflex-based NIR band and red band radiance values, respectively. Using Esri's ArcGIS 10.4 , we calculated the average NDVI for each compartment (Figure 2) and used it in yield estimation.

\section{Solar radiation data}

In the current study, we derived daily mean solar radiation data from the Aqua/MODIS-based photosynthetically active radiation (MODIS PAR) dataset, which was provided by the Japan Aerospace Exploration Agency (Frouin and Murakami, 2007); we also used Himawari-8-based solar radiation data, provided by AMATERASS, in yield estimation. MODIS PAR is an estimated daily mean PAR value based on once-per-day snapshot data; it features a 1-km spatial resolution. Himawari-8-based solar radiation data, on the other hand, are accumulated at 30-min intervals through the day and also feature a $1-\mathrm{km}$ spatial resolution. To compare and verify the accuracy of each solar radiation product, we set up a pyranometer (Climatec CHF-SR05DA1) at the Saitama test site.
The Advanced Himawari Imagers aboard the Himawari-8 acquire full-disk observations in 16 bands (three for visible, three for NIR, and 10 for infrared wavelengths) every $10 \mathrm{~min}$ (and over Japan, every $2.5 \mathrm{~min}$ ), with a spatial resolution ranging from $0.5 \mathrm{~km}$ to $2.0 \mathrm{~km}$ (Bessho et al., 2016; Damiani et al., 2018). Using the EXAM algorithm, one can leverage these observations to estimate surface downwelling global shortwave radiation over Japan at a 2.5-min temporal resolution and a nominal $1-\mathrm{km}$ spatial resolution (Takenaka et al., 2011; Damiani et al., 2018). In this study, we used a solar radiation dataset with a $30-\mathrm{min}$ temporal resolution.

\section{Yield estimation}

Equations (3) and (4) depict the yield estimation model for Koshihikari (Hama et al., 2018).

$$
\begin{aligned}
& y=28.2 N D V I_{\text {heading }} P A R+131.7 \\
& y=62.9 N D V I_{\text {heading }} S R+172.3,
\end{aligned}
$$

where $y$ is the yield $\left(\mathrm{g} / \mathrm{m}^{2}\right), N D V I_{\text {heading }}$ is the NDVI at the heading stage, $P A R$ is the average PAR value during the grain-filling stage $\left(\mathrm{E} / \mathrm{m}^{2} /\right.$ day), and $S R$ is the average solar radiation value during the grain-filling stage $\left(\mathrm{MJ} / \mathrm{m}^{2} /\right.$ day $)$. For the case of Koshihikari, we used the average PAR or solar radiation value $0-20 \mathrm{~d}$ after the heading stage. The parameters in Equations (3) and (4) are those of Hama et al. (2018). The estimated yield was verified through comparison to the observed yield from 2016 to 2017 at the Chiba and Saitama sites, using the root mean square error (RMSE) and the coefficient of determination $\left(R^{2}\right)$.

\section{RESULTS AND DISCUSSION}

\section{Model evaluation}

Figure 3 compares the estimated and observed yields. The $R^{2}$ of the MODIS PAR was 0.4749 , and that of 


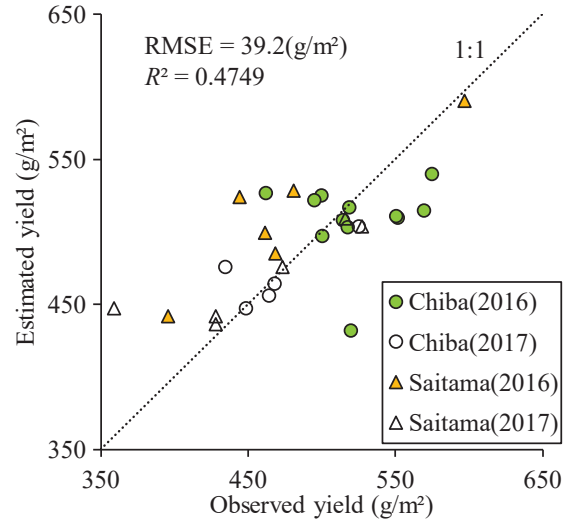

a)

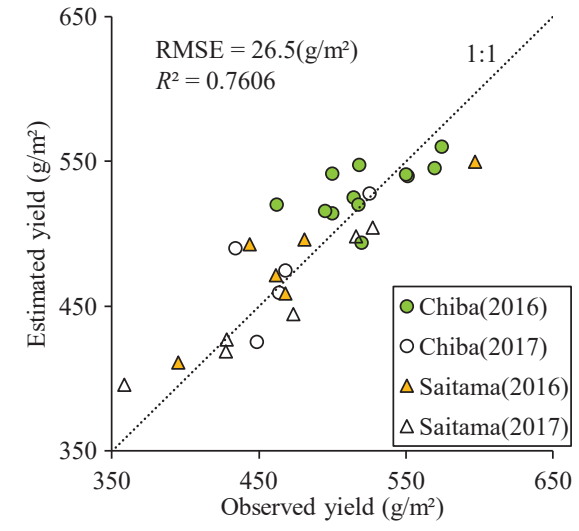

b)

Figure 3. Correlation between estimated and observed yield (2016-2017): (a) shows the estimated yield based on the MODIS PAR; (b) shows the estimated yield based on the satellite-based solar radiation (Himawari-8)

Himawari-8 solar radiation was 0.7606 . The RMSE of the estimated yield based on the MODIS PAR was $39.2 \mathrm{~g} / \mathrm{m}^{2}$, while that based on satellite-based solar radiation was $26.5 \mathrm{~g} / \mathrm{m}^{2}$ (Additionally, we noted that $39.2 \mathrm{~g} / \mathrm{m}^{2}$ was $16 \%$ of the average observed yield $\left[489.3 \mathrm{~g} / \mathrm{m}^{2}\right]$, and $26.5 \mathrm{~g} / \mathrm{m}^{2}$ was $11 \%$ of the average observed yield). Notably, the estimated yield based on Himawari-8 solar radiation outperformed the estimated yield based on MODIS PAR. Although the current study's yield estimation model is simple and does not utilize a crop model, it showed robustness. Nonetheless, it is worth mentioning that the parameters of the yield estimation model are specific to this cultivar (Hama et al., 2018).

Figure 4 shows the correlation between the NDVI at the heading stage and the observed yield. The most popular yield estimation method to use remote sensing is a derivation of a regression model based on this relationship (Nuarsa et al., 2011; Foster et al., 2017; Wang et al., 2017). Concerning the Saitama site samples, the higher the NDVI was at the heading stage, the higher the observed yield. The transplanting date and cultivar at the Saitama site was identical across all samples (Figure 2); therefore, the amount of solar radiation that occurred during the grain-filling stage was likewise identical. As a result, we were able to clarify the relationship between the NDVI at the heading stage and yield. In contrast, when comparing the 2016-2017 Chiba site samples to those from the Saitama site, we noted that the transplanting date differed (Figure 2); hence, the amount of solar radiation received during the grain-filling stage also differed, making the relationship between NDVI at the heading stage and yield unclear.

\section{Comparison of solar radiation datasets}

Figure 5 compares the solar radiation and observed solar radiation data. The $R^{2}$ of Himawari-8 solar radiation was 0.9306 , while that of MODIS PAR was 0.7448 . Both products were based on satellite data, but their temporal resolutions differed. MODIS PAR data were estimated from once-daily snapshots, and so cloud cover at the time of satellite observation affected estimation accuracy (There are also problems with data accuracy in humid regions such

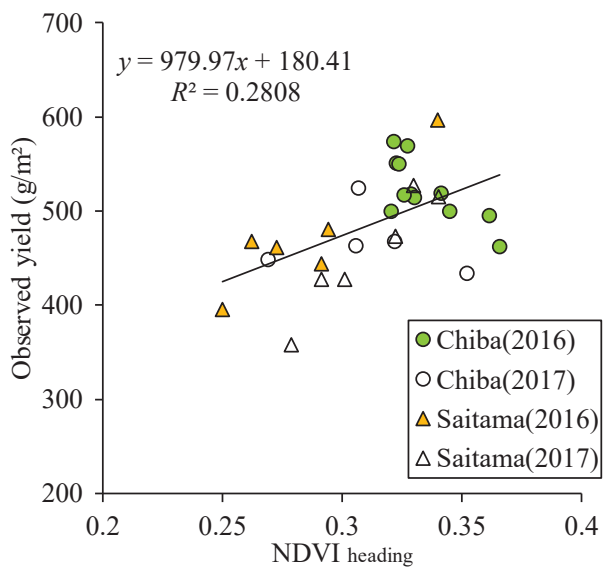

Figure 4. Correlation between NDVI heading and observed yield (2016-2017)

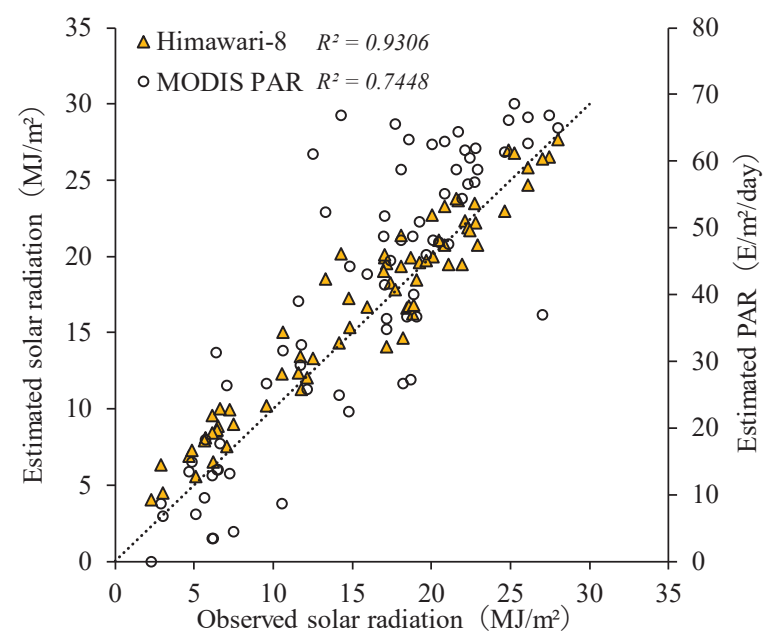

Figure 5. Comparison between solar radiation data sets and observed solar radiation in Saitama site (August 2017): The left $y$-axis is used for Himawari-8 solar radiation, whereas the right $y$-axis is used for MODIS PAR. The units of the two satellite products are different 
as monsoon Asia). On the other hand, the Himawari-8 solar radiation data provided by AMATERASS were captured at 30-min intervals. The difference in temporal resolution affected the accuracy of the satellite-based solar radiation datasets. Consequently, the estimated yield based on Himawari-8 solar radiation outperformed the estimated yield based on MODIS PAR.

The most accurate solar radiation dataset is from groundbased observation data captured in each field. In Japan, registrant can use agro-meteorological grid square data provided by the National Agriculture and Food Research Organization. This agro-meteorological grid square data is based on the automated meteorological data acquisition system (AMeDAS) ground observation network operated by the Japan Meteorological Agency. Solar radiation data are estimated from sunshine duration, and the value of each $1-\mathrm{km}$ grid square is an interpolation of the AMeDAS observation sites. Conversely, one can use satellite-based data, even in regions where there is no ground observation network. In such regions, improvements in the accuracy of satellite-based solar radiation data allow for yield estimations based on remote sensing.

\section{CONCLUSION}

A comparison of two satellite-based solar radiation datasets (i.e. Himawari-8 solar radiation and MODIS PAR) showed that the $R^{2}$ of the estimated yield based on Himawari-8 solar radiation was 0.7606 , while that based on MODIS PAR was 0.4749. Additionally, the root mean square error of the estimated yield based on Himawari-8 solar radiation was $26.5 \mathrm{~g} / \mathrm{m}^{2}$, while that based on MODIS PAR was $39.2 \mathrm{~g} / \mathrm{m}^{2}$ (The average observed yield was $489.3 \mathrm{~g} / \mathrm{m}^{2}$ ). The yield estimation based on Himawari-8 solar radiation, therefore, outperformed that based on the MODIS PAR. Although the yield estimation model of this study was simple and did not utilize a crop model, it showed robustness. It is worth noting that in this study, the parameters of the yield estimation model are specific to the cultivar, and so the model herein cannot be applied to other cultivars. However, if the model parameters were to be adjusted for other cultivars, the yield estimation framework of this study, which uses the Himawari-8 solar radiation dataset and UAV-RS, could be applied to other cultivars. In the first year of a study period, then, it is essential that tests be undertaken with multiple transplanting dates - as is the case in the current study - and that the parameters of the yield estimation model be optimized.

Owing to improvements in satellite-based solar radiation data through the use of the Himawari- 8 dataset, the accuracy of the yield estimations improved. Importantly, improvements in the accuracy of satellite-based solar radiation data allowed for yield estimations based on remote sensing; this is especially useful in regions where there are no on-the-ground solar radiation observation data.

UAV-RS enables optical sensor-based remote sensing in humid regions such as monsoon Asia. In the current study, UAV-RS made it possible to synchronize remote sensing monitoring with the growth stages of paddy rice; as a result, it was possible to analyze integrated meteorological measurements. In monsoon Asia - where the humid envi- ronment and cloud cover limit the efficacy of satellite remote sensing - the use of high-temporal-resolution Himawari-8 solar radiation data with UAV-RS in estimating yields offers clear advantages.

\section{ACKNOWLEDGMENTS}

The authors express thanks to the members of the Chiba Prefectural Agriculture and Forestry Research Center for their helpful support with the field observation. This work was supported by JSPS KAKENHI Grant Number $19 J 00437$.

\section{REFERENCES}

Bessho K, Date K, Hayashi M, Ikeda A, Imai T, Inoue H, Kumagai Y, Miyakawa T, Murata H, Ohno T, Okuyama A, Oyama R, Sasaki Y, Shimazu Y, Shimoji K, Sumida Y, Suzuki M, Taniguchi H, Tsuchiyama H, Uesawa D, Yokota H, Yoshida R. 2016. An introduction to Himawari-8/9Japan's new-generation geostationary meteorological satellites. Journal of the Meteorological Society of Japan. Ser. II 94: 151-183. DOI: 10.2151/jmsj.2016-009.

Boschetti M, Busetto L, Nutini F, Manfron G, Crema A, Confalonieri R, Bregaglio S, Pagani V, Guarneri T, Alessandro Brivio P. 2015. Assimilating seasonality information derived from satellite data time series in crop modelling for rice yield estimation. 2015 IEEE International Geoscience and Remote Sensing Symposium (IGARSS) : 157-160. DOI: 10.1109/IGARSS.2015.7325723.

Bouman B. 2001. ORYZA2000: modeling lowland rice. Vol. 1. IRRI, Manira; 235.

Curnel Y, de Wit AJW, Duveiller G, Defourny P. 2011. Potential performances of remotely sensed LAI assimilation in WOFOST model based on an OSS Experiment. Agricultural and Forest Meteorology 151: 1843-1855. DOI: 10.1016/ j.agrformet.2011.08.002.

Damiani A, Irie H, Horio T, Takamura T, Khatri P, Takenaka H, Nagao T, Nakajima T, Cordero R. 2018. Evaluation of Himawari-8 surface downwelling solar radiation by groundbased measurements. Atmospheric Measurement Techniques 11: 2501-2521. DOI: 10.5194/amt-11-2501-2018.

Foster AJ, Kakani VG, Mosali J. 2017. Estimation of bioenergy crop yield and $\mathrm{N}$ status by hyperspectral canopy reflectance and partial least square regression. Precision Agriculture 18: 192-209. DOI: 10.1007/s11119-016-9455-8.

Frouin R, Murakami H. 2007. Estimating photosynthetically available radiation at the ocean surface from ADEOS-II Global Imager data. Journal of Oceanography 63: 493-503. DOI: $10.1007 / \mathrm{s} 10872-007-0044-3$.

Hama A, Tanaka K, Mochizuki A, Arai H, Hirata T, Yawata R, Tsuruoka Y, Kondoh A. 2018. Estimating Paddy Rice Plant Height and Yield Using UAV Remote Sensing and Solar Radiation. Journal of Japan Society of Hydrology and Water Resources 31: 68-82. DOI: 10.3178/jjshwr.31.68.

High Level Panel of Experts on Food Security and Nutrition. 2013. Investing in smallholder agriculture for food security. A report by the High Level Panel of Experts on Food Security and Nutrition of the Committee on World Food Security, 111, High Level Panel of Experts on Food Security and 
Nutrition, Rome.

Homma K, Maki M, Hirooka Y. 2017. Development of a rice simulation model for remote-sensing (SIMRIW-RS). Journal of Agricultural Meteorology 73: 9-15. DOI: 10.2480/agrmet. D-14-00022.

Horie T, Nakagawa H, Centeno HGS, Kropff MJ. 1995. The rice crop simulation model SIMRIW and its testing. In Modeling the impact of climate change on rice production in Asia. Matthews RB, Kropff MJ, Bachelet D, van Laar HH (eds). CAR International, Manila, Philippines; 51-66.

Kyuma K. 2004. Paddy soil science. Kyoto University Press, Kyoto; 280.

Maki M, Sekiguchi K, Homma K, Hirooka Y, Oki K. 2017. Estimation of rice yield by SIMRIW-RS, a model that integrates remote sensing data into a crop growth model. Journal of Agricultural Meteorology 73: 2-8. DOI: 10.2480/agrmet.D14-00023.

Mosleh MK, Hassan QK, Chowdhury EH. 2016. Development of a remote sensing-based rice yield forecasting model. Spanish Journal of Agricultural Research 14: e0907. DOI: 10.5424/ sjar/2016143-8347.

Nuarsa IW, Nishio F, Hongo C. 2011. Rice Yield Estimation Using Landsat ETM+ Data and Field Observation. Journal of Agricultural Science 4: 45-56. DOI: 10.5539/jas. $\mathrm{v} 4 \mathrm{n} 3 \mathrm{p} 45$.

Peng D, Huang J, Li C, Liu L, Huang W, Wang F, Yang X. 2014. Modelling paddy rice yield using MODIS data. Agricultural and Forest Meteorology 184: 107-116. DOI: 10.1016/ j.agrformet.2013.09.006.

Ren J, Chen Z, Zhou Q, Tang H. 2008. Regional yield estimation for winter wheat with MODIS-NDVI data in Shandong, China. International Journal of Applied Earth Observation and Geoinformation 10: 403-413. DOI: 10.1016/j.jag.2007. 11.003.

Stroppiana D, Migliazzi M, Chiarabini V, Crema A, Musanti M,
Franchino C, Villa P. 2015. Rice yield estimation using multispectral data from UAV: A preliminary experiment in northern Italy. 2015 IEEE International Geoscience and Remote Sensing Symposium (IGARSS) : 4664-4667. DOI: 10.1109/IGARSS.2015.7326869.

Takenaka H, Nakajima T, Higurashi A, Higuchi A, Takamura T, Pinker RT, Nakajima T. 2011. Estimation of solar radiation using a neural network based on radiative transfer. Journal of Geophysical Research-Atmospheres 116: D8. DOI: 10.1029/2009jd013337.

Teoh CC, Mohd Nadzim N, Mohd shahmihaizan MJ, Mohd Khairil I, Faizal K, Mohd Shukry HB. 2016. Rice Yield Estimation using Below Cloud Remote Sensing Images Acquired by Unmanned Airborne Vehicle System. Advanced Science Engineering Information Technology 6: 516-519.

Tokunaga K, Moriyama M. 2012. Radiometric calibration method of the general purpose digital camera and its application for the vegetation monitoring. SPIE Asia-Pacific Remote Sensing 8524: 85241Y1-Y10. DOI: 10.1117/12.977211.

Wang C, Feng M, Yang W, Ding G, Xiao L, Li G, Liu T. 2017. Extraction of Sensitive Bands for Monitoring the Winter Wheat (Triticum aestivum) Growth Status and Yields Based on the Spectral Reflectance. PLOS ONE 12: e0167679. DOI: 10.1371/journal.pone.0167679.

Yumimoto K, Nagao T, Kikuchi M, Sekiyama T, Murakami H, Tanaka T, Ogi A, Irie H, Khatri P, Okumura H, Arai K, Morino I, Uchino O, Maki T. 2016. Aerosol data assimilation using data from Himawari-8, a next-generation geostationary meteorological satellite. Geophysical Research Letters 43: 5886-5894. DOI: 10.1002/2016g1069298.

Zhao YX, Chen SN, Shen S. 2013. Assimilating remote sensing information with crop model using Ensemble Kalman Filter for improving LAI monitoring and yield estimation. Ecological Modelling 270: 30-42. DOI: 10.1016/j.ecolmodel. 2013.08.016. 